\title{
Dijital Bankacılık Kullanımına Teknoloji Kabulü Temelli Bir Yaklaşım
}

\author{
(i) Fatih Sinan ESEN \\ TÜBITTAK, Ankara, Türkiye \\ fatihsinan@gmail.com \\ (Geliş/Received:25.12.2019; Kabul/Accepted:3.09.2020) \\ DOI: $10.17671 /$ gazibtd.664854
}

\begin{abstract}
$\ddot{O}_{z}$ et- Teknolojinin önceki yüzyıllara göre çok daha hızlı geliştiği ve yayıldığı günümüz şartlarında, teknolojik araçların, makinelerin, yazılımların ve gelişen imkânların kitleler arasında kullanımı da artış göstermiştir. Dijital bankacılık da bu teknolojik araçlardan birisi olarak kabul edilmektedir. Türkiye'de dijital bankacılık kullanan kişi sayısında son yıllarda kayda değer bir artış gerçekleşmiştir. Bu artışı etkileyen faktörlerin bilinmesi süreci hızlandırabilir. Çalışmada bireysel yenilikçiliğin dijital bankacııı kullanımına etkisi, Teknoloji Kabul Modeli üzerinden araştırılmış ve öngörülen etkiler, dijital bankacılığı aktif olarak kullanan toplam 302 kişiden toplanan verilerle, Yapısal Eşitlik Modellemesi kullanılarak test edilmiştir. Kişilerin bireysel yenilikçilik düzeyinin dijital bankacılık kullanımlarına sırasıyla algılanan kullanım kolaylığı, algılanan kullanışlılık-kullanma niyeti üzerinden dolaylı bir etkisinin olduğu görülmüştür. Yaş, eğitim durumu ve gelir durumu gibi demografik değişkenlerin de bu etkiler üzerinde yönetici etkisi olduğu saptanmıştır. Cinsiyet ise tüm değişkenler üzerinde farklılaştırıcı bir etkiye sahiptir. Bu çalışmanın katkısı, teknolojinin yayılmasında etki eden faktörlerin belirlenmesi olmuştur.
\end{abstract}

Anahtar Kelimeler - Bilişim teknolojilerinde finans, teknoloji kabul modeli, dijital bankacılık, internet bankacılığı, bireysel yenilikçilik

\section{A Technology Acceptance Based Approach To Digital Banking Use}

\begin{abstract}
The use of technological tools, machines, software and developing facilities among the masses has increased in the present conditions where technology has developed and spread much faster than previous centuries. Digital banking is also considered as one of these technological tools. There ise a noteworthy increase in the number of people using digital banking in Turkey. Knowing the factors affecting this increase can speed up the process. In this study, the effect of personal innovation on digital banking use was investigated through Technology Acceptance Model and the predicted effects were tested using Structural Equation Modeling with data collected from 302 people who actively use digital banking. Individuals' level of personal innovation has an indirect effect on digital banking usage, perceived ease of use, perceived usefulness and intention to use, respectively. Demographic variables such as age, educational level and income level also had a managing effect on these effects. Gender has a differentiating effect on all variables. The contribution of this study is to determine the factors affecting the spread of technology.
\end{abstract}

Keywords - Finance in information systems, technology acceptance model, digital banking, internet banking, personal innovativeness 


\section{GİRIŞ (INTRODUCTION)}

Gerek bireysel kullanıcılar, gerekse ticari işletmeler günümüzde teknolojinin sunduğu imkânlardan geniş şekilde faydalanmaktadırlar. Matbaanın Gutenberg tarafından 15.yüzyılda icat edilmesi ile başlayan bilgi yayılımı, bu yeniliğin neden olduğu sanayi devrimleri ile makineleşmenin ve sonrasında da teknolojinin yayılımının artması, günümüz bilgi ve iletişim teknolojilerinin oluşmasına zemin hazırlamıştır. Hayatı kolaylaştıran bu imkânlar 21.yüzyıla girildiğinde günlük hayatın her aşamasında yer almıştır. Bunlardan birisi de dijital bankacılık (internet bankacılığ 1 ve mobil bankacılık) adı verilen ve neredeyse her gün kullandığımız bir web / mobil ara yüzüdür. Dijital bankacılık sayesinde banka müşterileri banka şubelerine gitmek yerine vadeli / vadesiz hesap açma / kapama / görüntüleme, para yatırma / çekme, yurt içine ve dişına fon transfer etme, yatırım hesabı açma ve çeşitli yatırım araçlarını (altın, döviz, fonlar, borsa vb.) kullanma, kredi ve kredi kartı başvurusu yapma / izleme / limit belirleme, sanal kart oluşturma / iptal etme/limit belirleme, kişisel bilgileri ve iletişim bilgilerini güncelleme, fatura / vergi / harç / bağış ödemelerini yapma gibi birçok işlemi gerçekleştirebilmektedir.

Toplam aktif büyüklüğü 2018 yılının Aralık ayında 3,9 trilyon Türk Lirasına ulaşan ve Türkiye'deki tüm finansal kuruluşların aktiflerinin \%83'üne sahip olan Türkiye merkezli bankalar, finansal aracılık hizmetleri başta olmak üzere birçok hizmeti bünyelerinde barındırmaktadır [1]. Türkiye Bankalar Birliği’nin raporuna göre, 2019 y1lı Nisan ayı itibariyle Türkiye'de toplam 53 banka faaliyet göstermektedir. Bunların 34'ü mevduat bankasıyken, 13'ü ise kalkınma/yatırım bankası olarak faaliyet göstermektedir. Ayrıca, mevduat bankalarının 3'ü kamu sermayeli iken, 9 tanesi özel sermayelidir. Diğerleri ise yabancı sermayeli mevduat bankalarıdır. Türkiye'de dijital bankacılık banka müșterileri tarafından sıklıkla kullanılmaktadır. TBB'nin yayınladığı diğer bir rapora göre, 2018 yılı Aralık ayında dijital bankacılığı kullanan aktif kullanıcı sayısı yaklaşık 44 milyon kişidir [2]. Bu pastada bireysel müşterilerin oranı \%96'dır. Son yıllarda dijital bankacılık kullanımında önemli bir artış meydana gelmiştir. Örneğin, 2017 yılından 2018 yılına geçilirken, internet bankacılığında toplam işlem hacmi \%20 artmış ve 5,6 trilyon TL olmuştur. Mobil bankacılıkta ise bu artış \%67'dir. Aralık 2018 itibarıyla, 27 banka internet bankacılığı, 21 banka ise mobil bankacılık hizmeti vermektedir. Dijital bankacılıktaki bu önemli gelişmeler ve kullanım oranlarındaki artışlar, bu teknolojinin kitleler içinde kabul görmesi ve bunu etkileyen dış faktörlerin tanımlanmasını gerekli kılmaktadır. Bu çalışma, teknoloji bakış açısıyla ve bu amaca hizmet etmek amacıyla yapılmıştır. Çalışmada kişileri dijital bankacılık kullanmaya yönlendiren dinamiklerin anlaşılabilmesi için literatürden hareketle kullanıma dayalı nedensel ilişkiler test edilmiştir.
Öncelikle kavramsal bir arka plan verilmiş ve uygulamada kullanılan model ve değişkenler anlatılmıştır. Ardından hipotezler verilmiş ve hipotezleri sınamakta kullanılan yöntemden/araçlardan toplanmasından bahsedilmiştir. Yapısal Eşitlik Modellemesi sürecinde öncelikle faktör analizi yapılmış ve boyutlar belirlenmiştir. Ardından geçerlik ve güvenilirlik testleri uygulanmış ve hipotezlerin testi gerçekleştirilmiştir. Son olarak, demografik değişkenlerin etkileri de varyans analizleri ile test edilmiş ve raporlanmıştır.

\section{KAVRAMSAL ARKAPLAN (CONCEPTUAL BACKGROUND)}

Dijital bankacılık çok çeşitli ve kolaylaştırılmış işlemler sunmasına rağmen, dijital bankacılığı halen kullanmayan veya nadiren kullanan müşteriler vardır. Dijital bankacılık, internetin hızlanması ve daha güvenli hale gelmesi ile ortaya çıkmış ve yayılmış olan teknolojik bir gelişmedir. Davranışların tutumsal ve normatif nedenlerine yoğunlaşan ve Ajzen [3] tarafindan geliştirilen Planlı Davranış Teorisini (Theory of Planned Behavior) teknolojik gelişmeler için yetersiz bulan Davis [4] Teknoloji Kabul Modelini (Technology Acceptance Model) ortaya atmış ve sonraki araştırmalarında da [5] geliştirerek kullanmıştır. Bu model, teknolojik araçların ve ara yüzlerin kullanıcılar arasında yayılması ve kabul görmesi ile ilgili olarak önemli nedensel ilişkileri ortaya koymaktadır (Şekil 1).

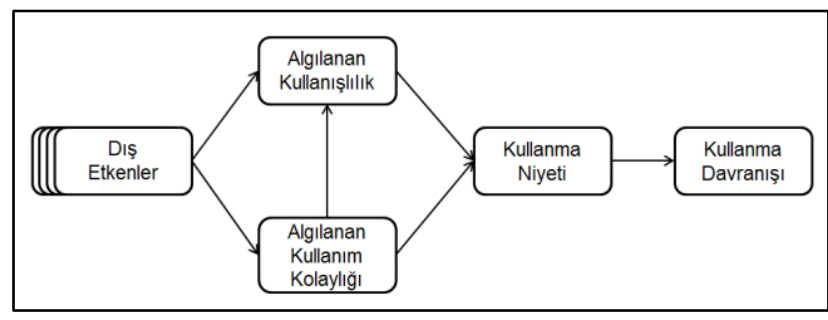

Şekil 1. Teknoloji Kabul Modeli [6]

(Technology Acceptance Model)

Söz konusu modele sonraki çalışmalarda eklemeler yapılmıştır [7,8]. Ancak, literatürde en çok kullanılan ve kabul gören model ilk model olduğu için, bu çalışmada bu model benimsenmiştir.

Modelde yer alan diş etkenler kitlelerin teknoloji kabul düzeyini etkilemektedir. Güven, tutum, inançlar gibi birçok dış etkenden bahsedilebilir. Örneğin Robinson, Marshall ve Stamps [9] dış etkenler olarak algılanan kontrol, deneyimleme süresi, bireysel yenilikçilik, destek hizmetleri, örgütsel yenilikçilik değişkenlerini test etmiştir ve anlamlı etkiye sahip olduğu gösterilen değişkenlerden birisi de bireysel yenilikçiliktir. Bu çalışma kapsamında, kişilerin internet ve interneti kullanan teknolojileri benimsemesinde büyük etkisi olduğu düşünülen "bireysel yenilikçilik (personal innovativeness)" değişkeni dış etken olarak tercih edilmiştir. Agarwal ve Prasad'ın [10] çalışmaları da dış etken olarak bireysel yenilikçiliği temel almıştır. Toplumda yaşayan bireylerin teknolojik yeniliklere uyum 
sağlama kabiliyeti bireysel yenilikçilik kapsamında incelenmiştir.

Modelde yer alan değişkenlerden "algılanan kullanışlılık (perceived usefulness)" bireylerin teknolojik bir ara yüzü, makineyi veya sistemi kullanmaları sayesinde önceden belirledikleri bir amaca veya amaçlara ulaşabilme ve bu teknolojinin bireylerin işlerindeki performanslarını artırma düzeyi olarak tanımlanmış, "algılanan kullanım kolaylığı (perceived ease of use)" ise kullanım öncesinde ve esnasında en az çabayı sarf etmenin derecesi şeklinde ifade edilmiştir [11]. Bu iki değişkenin ardılı olan "kullanma niyeti (behavioral intention to use)" değişkeni "Nedenli Eylem Teorisi (Theory of Reasoned Action)" kapsamında Ajzen ve Fishbein [12] tarafindan ortaya atılmıştır. Davranışsal sebep-sonuç ilişkilerini belirlemek için kullanılmaktadır. Bireylerin öznel olarak, uzun vadede bir davranışı devam ettirme niyetlerinin düzeyidir. Kullanma davranışı ise bu niyetin gerçekleştirilmesine, yani fiiliyata dökülmesine dayanmaktadır.

Konuyla ilgili literatür incelendiğinde, Şekil 1'de verilen modelde yer alan ilişkilerin yer aldığı birçok çalışma olduğu görülmektedir [9, 10, 13-18]. Ancak, model dijital bankacılık özelinde kurgulandığı zaman, bilimsel araştırma bulunmamaktadır. Yeniliklere açık olan kişilerin yeni araçları, teknolojileri ve bunların ürünleri olan makineleri ve süreçleri kullanma ve onlardan faydalanma düzeylerinin, yeniliklere açık olmayan veya yeniliğe direnci yüksek olan kişilere göre daha fazla olması beklenmektedir. Dolayısıyla, bireysel yenilikçiliğin, bu teknolojik yeniliklerden faydalanmayı kolaylaştırıcı etkisi olabilir. Dijital bankacılık da son zamanlarda artan bir kullanıcı kitlesine sahip olan, gerek bilgi güvenliğinin, gerekse veri tabanı teknolojilerinin bir ürünü olan, hayatı kolaylaştıran teknolojik bir araçtır. $\mathrm{Bu}$ nedenle, bireysel yenilikçilik düzeyinin yüksekliği, tıpk1 diğer teknolojik ürünlerin konu edildiği çalışmalarda [9, 10, 13-15] gösterildiği gibi dijital bankacılı̆̆ın benimsenmesinde de olumlu bir etkiye sahip olabilir. Dijital bankacılık özelinde de daha önce yapılan bilimsel çalışmaların sonuçları bu yönde ipuçları vermektedir [1921]. Sonuç olarak, bu çalışmada bireysel yenilikçiliğin (algılanan kullanışlılık, kullanma niyeti ve algılanan kullanım kolaylığı üzerinden) dijital bankacılık kullanımına etkisi olduğu düşünülmüştür.

H1: Bireysel yenilikçilik düzeyinin dijital bankacılık ile ilgili algılanan kullanışlılık düzeyi üzerinde olumlu ve anlamlı bir etkisi vardır.

H2: Bireysel yenilikçilik düzeyinin dijital bankacılık kullanma niyeti düzeyi üzerinde olumlu ve anlaml bir etkisi vardır.

H3: Bireysel yenilikçilik düzeyinin dijital bankacılık ile ilgili algılanan kullanım kolaylı̆̆ $\breve{l}$ düzeyi üzerinde olumlu ve anlamlı bir etkisi vardır.
Teknoloji Kabul Modeli ile ilgili çalışmalarda, modeli teşkil eden algılanan kullanım kolaylığı, algılanan kullanışlılık, kullanma niyeti ve kullanma davranışı arasındaki anlamlı etkiler test edilmiştir [22-29]. Online eğitim platformları, online alışveriş, paket yazılım programları, cep telefonları, makineler, bilgisayarlar vb. araçların kullanımını açıklamak için yapılan bu çalışmalarda algılanan kullanım kolaylığının algılanan kullanışlılığa ve kullanma niyetine olumlu ve anlamlı etkisinden bahsedilmiştir [26, 28, 29]. Bunun yanında, algılanan kullanışlılık düzeyinin de kullanma niyeti üzerinden davranışı etkilediği belirtilmiştir. Dijital bankacılık ile ilgili yapılan çalışmalarda da benzer sonuçlara ulaşılmıştır [19-21, 30-33]. Bu çalışmalarda dijital bankacılık yerine zaman zaman online bankacılık, mobil bankacılık, elektronik bankacılık gibi benzer terimler de kullanılmıştır. Teknoloji Kabul Modeli'nin içinde yer alan bu değişkenler ve ilişkilere bu çalışmada da yer verilmiştir.

H4: Dijital bankacllı ile ilgili algllanan kullanım kolaylığı düzeyinin dijital bankacılık ile ilgili algılanan kullanışlılık düzeyi üzerinde olumlu ve anlamlı bir etkisi vardır.

H5: Dijital bankacılık ile ilgili algılanan kullanım kolaylığl düzeyinin dijital bankacılık kullanma niyeti düzeyi üzerinde olumlu ve anlamlı bir etkisi vardır.

H6: Dijital bankacılık ile ilgili algılanan kullanışlılık düzeyinin dijital bankacılığl kullanma niyeti düzeyi üzerinde olumlu ve anlamlı bir etkisi vardır.

H7: Dijital bankacılı̆̆ kullanma niyeti düzeyinin dijital bankacılık kullanma davranışı üzerinde olumlu ve anlamlı bir etkisi vardır.

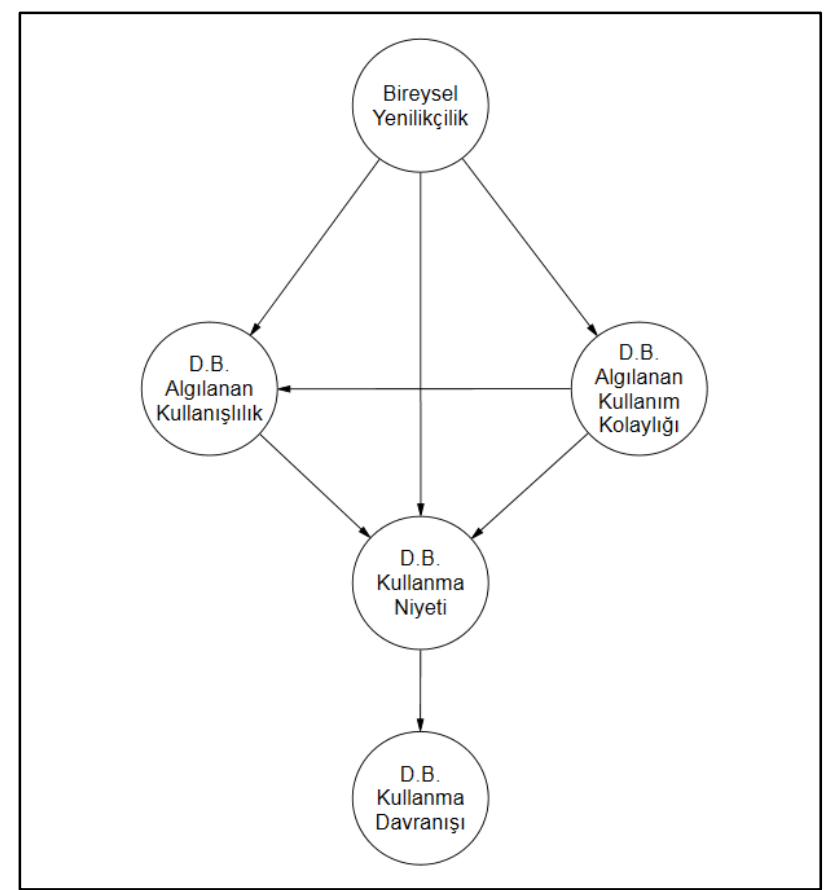

Şekil 2. Araştırma modeli (Research model) 
Özet olarak, çalışmada test edilen model Şekil 2'de verilmiştir.

\section{VERİ VE YÖNTEM (DATA AND METHODOLOGY)}

Araştırmada nicel bir yöntem kullanılmıştır. Birincil veri elde etmek amacıyla anket hazırlanmış ve uygulanmıştır. Araştırma modelini test etmek için oluşturulan anket 21 maddeden oluşmaktadır. Bu ifadelerden 17'si modeldeki değişkenleri ölçmek amaciyla konulmuştur. $\mathrm{Bu}$ ifadelerde, ölçeklerin asıllarında olduğu gibi 7'li Likert ölçeği kullanılmıştır. Anket çevrimiçi ortamda web platformuna yüklenmiştir. Anket bağlantısı, Türkiye'de ikamet eden ve kolayda örnekleme ile ulaşılabilen 2357 kişiye internet üzerinden gönderilmiş, 302 kişiden dönüş olmuştur. $\mathrm{Bu}$ kişilerin yanıtları çalışmanın veri setini oluşturmuştur.

Anket sonucunda toplanan veriler IBM SPSS (Statistical Package for the Social Sciences-Sosyal Bilimler için İstatistik Paketi) adlı paket programın 24'üncü sürümü ve bu paket programın bir eklentisi olan IBM SPSS AMOS'a aktarılarak analiz gerçekleştirilmiştir. Kurulan araştırma modeli, "Yapısal Eşitlik Modellemesi (Structural Equation Modeling)" (kısaca YEM) yöntemi kullanılarak test edilmiştir. Analiz yöntemi olarak YEM'in seçilmesinin nedeni, modeldeki değişkenlerin arasındaki fark edilmesi güç olan bağlantıları görebilmeyi sağlayan ve çözülebilmesi güç olan modellerin dahi kolay bir şekilde test edilebildiği bir yöntem olmasıdır [34]. YEM'de kullanılan çeşitli stratejiler bulunmaktadır: Doğrulayıcı Modelleme Stratejisi, Alternatif Modeller Stratejisi, Model Geliştirme Stratejisi [35]. Bu çalışmada, literatüre dayalı bir model oluşturularak uyum iyiliğ değerleri sunulmuştur. Dolayısıyla, analiz aşamasında modelde bir geliştirme yapılmamıştır. Birden farklı model oluşturulmamış, tek bir modelin doğrulanması gerçekleştirilmiştir. Bu nedenle, çalışmada Doğrulayıcı Modelleme Stratejisi kullanılmıştır. Kavramsal modelin anket yoluyla toplanan veri seti ile örtüşüp örtüşmediği kontrol edilmiştir. Analiz esnasında kullanılan parametre tahmin yöntemi ise En Çok Olabilirlik (Maximum Likelihood) yöntemidir. Örneklem boyutu büyük olduğu için normallik koşulunun sağlandığı varsayılmıştır. Çalışma kapsamındaki tüm testler ve değerlendirmeler $\% 95$ güven aralığı $(\alpha=0,05)$ temel alınarak yapılmıştır. Modelde kullanılan toplam 5 değişkeni ölçmek için kullanılan ölçekler kaynaklarıyla birlikte Tablo 1'de verilmiştir.

Tablo 1. Kullanılan ölçek kaynakları (Sources of used scales)

\begin{tabular}{|l|l|}
\hline Değişken & Kaynak \\
\hline Bireysel yenilikçilik & {$[10]$} \\
\hline Algılanan kullanışlılık & {$[11]$} \\
\hline Algılanan kullanım kolaylığı & {$[11]$} \\
\hline Kullanma niyeti & {$[12]$} \\
\hline Kullanma davranışı & {$[39]$} \\
\hline
\end{tabular}


amacıyla Çarpıklık ve Basıklık analizleri yapılmıştır. Basıklık ve çarpıklık değerlerinin +3 ile -3 arasında olması durumunda normallik hakkında olumlu bir sonuca varabilmek mümkündür [38]. Tüm değişkenler için bu koşul sağlanmış ve bu sayede verilerin normal dağıldığ kabul edilmiştir.

Ardından, açımlayıcı faktör analizi (exploratory factor analysis) uygulanmıştır. Bu aşamada, Temel Bileşenler Analizi ve Varimax [39] döndürmesi kullanılmıştır. Analiz aşamasında tüm maddeler en az 0,5 faktör yükü ile bir faktöre yüklenmiştir. Dolayısıyla, hiçbir madde analizden çıkarılmamıştır (analizde katsayılar için alt limit 0,5 olarak alınmıştır). Tüm değişkenler tek faktörlü bir yapı sergilemiştir. Açımlayıcı faktör analizine ait sonuçlar Tablo 4'te yer verilmiştir.

Tablo 4. Açımlayıcı faktör analizi sonuçları (The results of exploratory factor analysis)

\begin{tabular}{|c|c|c|c|}
\hline Değişkenler & $\begin{array}{c}\text { Faktör } \\
\text { Yükleri }\end{array}$ & $\begin{array}{c}\text { Varyans } \\
\text { Yüzdesi }\end{array}$ & Özdeğeri \\
\hline Bireysel yenilikçilik & & 12,878 & 2,283 \\
\hline BY1 & 0,835 & & \\
\hline BY2 & 0,501 & & \\
\hline BY3 & 0,762 & & \\
\hline BY4 & 0,869 & & \\
\hline Alg1lanan kullanışl11ık & & 13,673 & 2,424 \\
\hline AK1 & 0,948 & & \\
\hline AK2 & 0,811 & & \\
\hline AK3 & 0,932 & & \\
\hline $\begin{array}{l}\text { Alg1lanan kullanım } \\
\text { kolaylığ1 }\end{array}$ & & 19,523 & 3,461 \\
\hline AKK1 & 0,914 & & \\
\hline AKK2 & 0,926 & & \\
\hline AKK3 & 0,926 & & \\
\hline AKK4 & 0,954 & & \\
\hline Kullanma niyeti & & 15,597 & 2,765 \\
\hline KN1 & 0,946 & & \\
\hline KN2 & 0,961 & & \\
\hline KN3 & 0,973 & & \\
\hline Kullanma davranış1 & & 11,360 & 2,014 \\
\hline DB1 & 0,874 & & \\
\hline DB2 & 0,685 & & \\
\hline DB3 & 0,884 & & \\
\hline
\end{tabular}

Açımlayıcı faktör analizi sonucu oluşan yapıda toplam 5 faktör belirmiştir ve toplam açıklanan varyans yüzdesi $\% 73,033$ 'tür. Bir sonraki aşamada, güvenilirlik ve geçerlilik analizi yapılmıştır. Boyutların güvenilirliğini test etmek amacıyla tüm gizil değişkenler için Cronbach's Alpha, AVE ve CR katsayıları hesaplanmıștır. Cronbach's Alpha If-item-deleted analizi sonucunda, bireysel yenilikçilik altındaki BY2 kodlu madde ("Genellikle yeni teknolojileri kullanma konusunda kararsızım."), Cronbach's alpha değerini düşürdüğü için ölçekten çıkarılmıştır. Böylece Cronbach's Alpha değeri 0,716'dan 0,778 'e yükselmiştir. Boyutların güvenilir olduğu, ayrım geçerliliği (discriminant validity) ve benzeşim geçerliliği (convergent validity) koşullarını sağladığı görülmüştür [40-42]. Yalnızca algılanan kullanışlılık ve algılanan kullanım kolaylığı ölçekleri için en büyük korelasyonun karesinin AVE değerinden büyük olduğu görülmüştür. Bu durumda bu boyutların analizden çıkarılması durumu ortaya çıkmaktadır. Ancak, aradaki farkın çok küçük olmasından dolayı bu boyutlar da analize katılmıştır. Güvenilirlik ve geçerlilik analizine ait değerler Tablo 5 'te verilmiştir.

Tablo 5. Güvenilirlik ve geçerlilik analizi (Reliability and validity analysis)

\begin{tabular}{|l|c|c|c|c|c|c|c|c|}
\hline \multirow{2}{*}{ Boyutlar* } & $\begin{array}{c}\text { Cr.'s } \\
\text { Alpha }\end{array}$ & AVE & CR & \multicolumn{5}{|c|}{ Korelasyonlar** } \\
\cline { 5 - 10 } & & & BY & AK & AKK & KN & IB \\
\hline BY & 0,778 & 0,678 & 0,863 & $0,17 *$ & & & & \\
\hline AK & 0,869 & 0,808 & 0,926 & 0,37 & $0,92^{*}$ & & & \\
\hline AKK & 0,948 & 0,865 & 0,962 & 0,41 & 0,94 & $0,88^{*}$ & & \\
\hline KN & 0,957 & 0,922 & 0,972 & 0,31 & 0,96 & 0,91 & $0,92^{*}$ & \\
\hline DB & 0,752 & 0,672 & 0,858 & 0,16 & 0,59 & 0,62 & 0,67 & $0,45^{*}$ \\
\hline
\end{tabular}

*BY:Bireysel yenilikçilik, AK:Algılanan kullanışl1lık, AKK:Algılanan kullanım kolaylı̆̆ı, KN:Kullanma niyeti, DB:Kullanma davranışı

**illgili boyutun diğer boyutlarla olan korelasyonlarından en büyüğünün karesi (AVE’den küçük olmalıdır)

Yapı geçerliliğini (construct validity) test etmek amacıyla veri seti doğrulayıcı faktör analizine (DFA, confirmatory factor analysis) tabi tutulmuştur. Tüm gizil değişkenler tek faktörlü bir yapı sergilediği için, yalnızca 1'inci derece DFA yapılmıştır. Uyum endekslerinin iyileştirilmesi amacıyla bazı hata terimleri, modifikasyon endeksine bakılarak bağlanmıştır. DFA aşamasında test edilen model Şekil 3 'te verilmiştir.

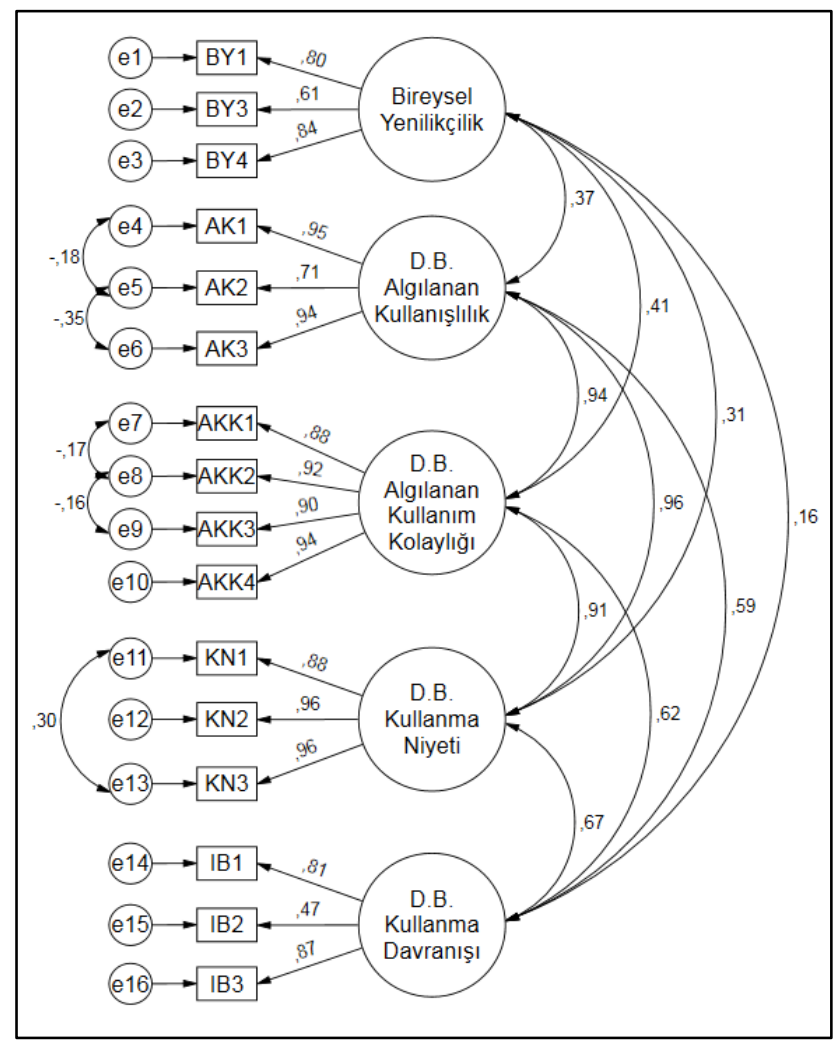

Şekil 3. 1.Derece DFA modeli (1st level CFA model)

DFA sonucunda, uyum endeksi değerlerinin iyi ve kabul edilebilir düzeyde olduğu görülmüş ve yapı geçerlilikleri sağlanmıştır. DFA için uyum iyiliği değerleri Tablo 6' da verilmiştir. 
Tablo 6. DFA uyum iyiliği değerleri (CFA goodness-of-fit values)

\begin{tabular}{|l|c|c|c|}
\hline $\begin{array}{l}\text { Uyum } \\
\text { Endeksi }\end{array}$ & $\begin{array}{c}1 . \text { Derece } \\
\text { DFA }\end{array}$ & İyi Uyum & Kabul Edilebilir Uyum \\
\hline$\chi^{2} / \mathrm{df}$ & 3,008 & $0 \leq \chi^{2} / \mathrm{df} \leq 2$ & $2<\chi^{2} / \mathrm{df} \leq 5$ \\
\hline TLI & 0,951 & $0,97 \leq \mathrm{TLI} \leq 1,00$ & $0,95 \leq \mathrm{TLI}<0,97$ \\
\hline CFI & 0,964 & $0,97 \leq \mathrm{CFI} \leq 1,00$ & $0,95 \leq \mathrm{CFI}<0,97$ \\
\hline RMSEA & 0,082 & $0 \leq \mathrm{RMSEA} \leq 0,05$ & $0,05<\mathrm{RMSEA} \leq 0,08$ \\
\hline SRMR & 0,032 & $0 \leq \mathrm{SRMR} \leq 0,05$ & $0,05<\mathrm{SRMR} \leq 0,10$ \\
\hline NFI & 0,947 & $0,95 \leq \mathrm{NFI} \leq 1,00$ & $0,90 \leq \mathrm{NFI}<0,95$ \\
\hline GFI & 0,900 & $0,95 \leq \mathrm{GFI} \leq 1,00$ & $0,90 \leq \mathrm{GFI}<0,95$ \\
\hline
\end{tabular}

YEM'de DFA ve yol analizinde, veri yapısının kavramsal model ile uyumluluğu konusunda farklı ölçütler bulunur. Bunlara "uyum iyiliği" (goodness-of-fit) adı verilmektedir. Bunlardan en çok kullanılan değerler $\chi^{2} / \mathrm{df}$ (ki-kare/serbestlik derecesi), SRMR (standartlaştırılmış ortalama hataların karekökü), RMSEA (yaklaşık hataların karekökü), TLI (Tucker-Lewis endeksi), CFI (karşılaştırmalı uyum endeksi), GFI (iyilik uyum endeksi) ve NFI'dır (normlandırılmış uyum endeksi). Bu değerler için iyi uyum ve kabul edilebilir uyum aralığı belirtilmiştir [43, 44]. Uyum olup olmadığına karar vermek amacıyla hangi değer aralıklarının yeterli olduğu hakkında literatürde farklı fikirler vardır [44-47]. Araştırmacılar tarafından tam bir fikir birliğine varılamamıştır. Bu çalışma için yukarıda bahsedilen değer aralıklarının yeterli olduğu varsayılmıştır.

Ardından, YEM'in son adımı olan yol analizi yapılmıştır. Öne sürülen hipotezler 1șı̆̆ında kurgulanan araştırma modeli, yol analizinde test edilmiştir. Yol analizinde test edilen model Şekil 4'te verilmiştir. Analiz sonucunda, anlamlı etkiler kalın oklarla, anlamsız etkiler ise ince oklarla gösterilmiştir. Okların üzerindeki değerler ise ilişkinin standardize regresyon katsayısını göstermektedir.

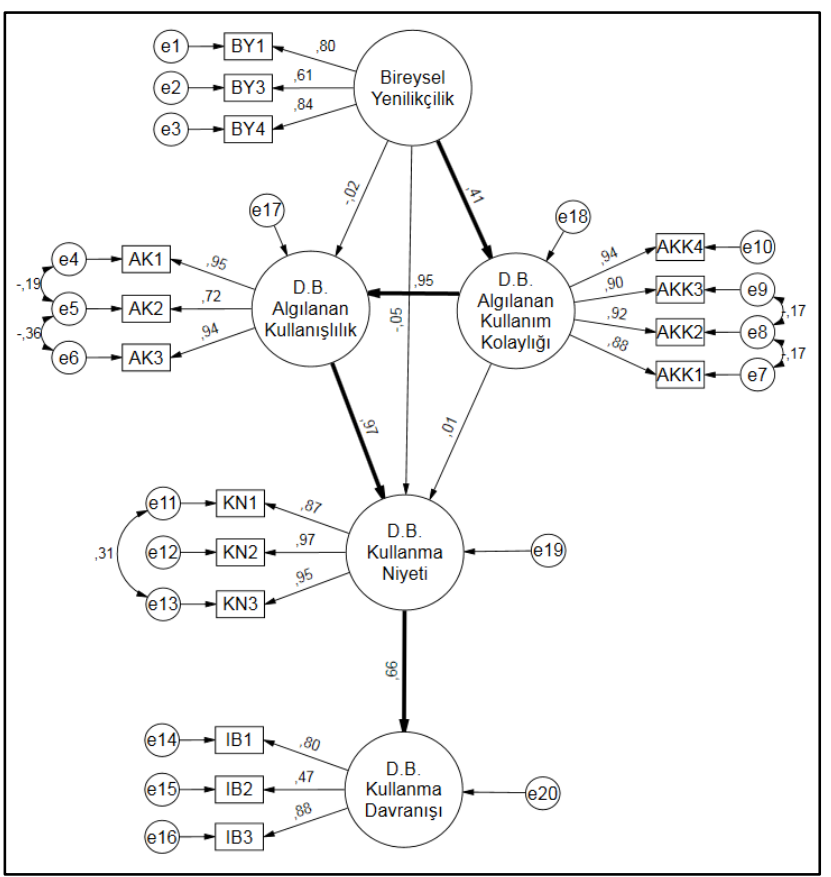

Şekil 4. Yol analizi (Path analysis)
Yol analizi sonucunda uyum iyiliği değerlerine bakılarak modelin kabul edilip edilemeyeceği belirlenmiştir. Tablo 7'de yer alan endeks değerlerine göre modelin kabul edilebilir uyum aralığında olduğu görülmüştür.

Tablo 7. Yol analizi uyum iyiliği değerleri (Goodness-of-fit values for path analysis)

\begin{tabular}{|l|c|c|c|}
\hline $\begin{array}{l}\text { Uyum } \\
\text { Endeksi }\end{array}$ & Yol Analizi & İyi Uyum & Kabul Edilebilir Uyum \\
\hline$\chi^{2} / \mathrm{df}$ & 3,050 & $0 \leq \chi^{2} / \mathrm{df} \leq 2$ & $2<\chi^{2} / \mathrm{df} \leq 5$ \\
\hline TLI & 0,950 & $0,97 \leq \mathrm{TLI} \leq 1,00$ & $0,95 \leq \mathrm{TLI}<0,97$ \\
\hline CFI & 0,961 & $0,97 \leq \mathrm{CFI} \leq 1,00$ & $0,95 \leq \mathrm{CFI}<0,97$ \\
\hline RMSEA & 0,083 & $0 \leq \mathrm{RMSEA} \leq 0,05$ & $0,05<\mathrm{RMSEA} \leq 0,08$ \\
\hline SRMR & 0,033 & $0 \leq \mathrm{SRMR} \leq 0,05$ & $0,05<\mathrm{SRMR} \leq 0,10$ \\
\hline NFI & 0,944 & $0,95 \leq \mathrm{NFI} \leq 1,00$ & $0,90 \leq \mathrm{NFI}<0,95$ \\
\hline GFI & 0,895 & $0,95 \leq \mathrm{GFI} \leq 1,00$ & $0,90 \leq \mathrm{GFI}<0,95$ \\
\hline
\end{tabular}

Model uyumu yakalandıktan sonra, gizil değişkenler arasındaki tek yönlü nedensel ilişkilere bakılmış ve hangi hipotezlerin kabul/ret edildiği belirlenmiştir. Analiz sonuçları Tablo 8'de verilmiştir.

Tablo 8. Yol analizi sonuçları (Findings of path analysis)

\begin{tabular}{|l|l|l|c|c|c|}
\hline & \multicolumn{1}{|c|}{ Etkilenen } & \multicolumn{1}{|c|}{ Etkileyen } & $\begin{array}{c}\text { St. } \\
\text { Katsayı }\end{array}$ & Olasılık & Sonuç \\
\hline H1 & $\begin{array}{l}\text { D.B. Algılanan } \\
\text { kullanışlılık }\end{array}$ & $\begin{array}{l}\text { Bireysel } \\
\text { yenilikçilik }\end{array}$ & $-0,024$ & 0,439 & Ret \\
\hline H2 & $\begin{array}{l}\text { D.B. Kullanma } \\
\text { niyeti }\end{array}$ & $\begin{array}{l}\text { Bireysel } \\
\text { yenilikçilik }\end{array}$ & $-0,053$ & 0,056 & Ret \\
\hline H3 & $\begin{array}{l}\text { D.B. Algılanan } \\
\text { kullanım } \\
\text { kolaylığ1 }\end{array}$ & $\begin{array}{l}\text { Bireysel } \\
\text { yenilikçilik }\end{array}$ & 0,410 & $<0,001$ & Kabul \\
\hline H4 & $\begin{array}{l}\text { D.B. Algılanan } \\
\text { kullanışlılık }\end{array}$ & $\begin{array}{l}\text { D.B. Algılanan } \\
\text { kullanım kolaylığ1 }\end{array}$ & 0,953 & $<0,001$ & Kabul \\
\hline H5 & $\begin{array}{l}\text { D.B. Kullanma } \\
\text { niyeti }\end{array}$ & $\begin{array}{l}\text { D.B. Algılanan } \\
\text { kullanım kolaylığ1 }\end{array}$ & 0,009 & 0,935 & Ret \\
\hline H6 & $\begin{array}{l}\text { D.B. Kullanma } \\
\text { niyeti }\end{array}$ & $\begin{array}{l}\text { D.B. Algılanan } \\
\text { kullanışlılık }\end{array}$ & 0,974 & $<0,001$ & Kabul \\
\hline H7 & $\begin{array}{l}\text { D.B. Kullanma } \\
\text { davranışı }\end{array}$ & $\begin{array}{l}\text { D.B. Kullanma } \\
\text { niyeti }\end{array}$ & 0,656 & $<0,001$ & Kabul \\
\hline
\end{tabular}

Analiz sonuçlarına göre, bireysel yenilikçiliğin ne algılanan kullanışlılığa, ne de kullanma niyetine olumlu bir etkisi vardır. Dolayısıyla, H1 ve H2 reddedilmiştir. Ancak, bireysel yenilikçiliğin algılanan kullanım kolaylığına olumlu ve anlamlı bir etkisi olduğu görülmektedir. Bunun bir sonucu olarak, H3 kabul edilmiştir.

TKM'nde yer alan ilişkilere bakıldığında, algılanan kullanım kolaylığının algılanan kullanışlılık üzerinde kuvvetli (st.katsayı=0,953), olumlu ve anlamlı bir etkisi olduğu görülmektedir. Böylece H4 kabul edilmiştir. Algılanan kullanım kolaylığının kullanma niyetine anlamlı bir etkisi bulunamamış ve H5 hipotezi reddedilmiştir. Kullanma niyetine etki ettiği öne sürülen bir diğer değişken ise algılanan kullanışlılıktır ve bu ilişki de anlamlıdır, hatta kuvvetli bir ilişkiden söz edilebilir (st.katsayl=0,974). Bu durumda H6 hipotezi kabul edilmiştir. TKM'ndeki son ilişki kullanma niyetinin kullanma davranışını olumlu ve anlamlı etkilemesidir ki, analiz sonucunda bu durum doğrulanmıştır. Dolayısıyla H7 de kabul edilmiştir. 
Yol analizi sonucunda kabul edilen 4 hipotezin temsil ettiği ilişskilerin her biri için, ilişkinin derecesinin (standardize regresyon katsayısının) 4 demografik değişkene (cinsiyet, yaş, eğitim durumu ve gelir) göre farklılaşıp farklılaşmadığ 1 araştırılmıştır. Cinsiyet gruplayıc1 (nominal) bir değişken olduğu için, YEM'in bir parçası olan "Çoklu Grup Analizi (Multi-Group Analysis)" yöntemi kullanılmıştır [48]. Analiz sonucunda, hiçbir ilişkinin derecesinin cinsiyete göre farklılaşmadığ görülmüştür (Tablo 9).

Tablo 9. Cinsiyet için çoklu grup analizleri (Multi-group analysis for gender)

\begin{tabular}{|l|l|l|c|c|}
\hline \multicolumn{5}{|c|}{ (Multi-group analysis for gender) } \\
\hline H3 & \multicolumn{1}{|c|}{ Etkilenen } & \multicolumn{1}{|c|}{ Etkileyen } & Olasılık & Değerlendirme \\
kullanım kolaylığg & $\begin{array}{l}\text { Bireysel } \\
\text { yenilikçilik }\end{array}$ & 0,073 & $\begin{array}{c}\text { Cinsiyete göre } \\
\text { anlamlı değişim } \\
\text { bulunamamıştır. }\end{array}$ \\
\hline H4 & $\begin{array}{l}\text { D.B. Algılanan } \\
\text { kullanışl1lık }\end{array}$ & $\begin{array}{l}\text { D.B. Algılanan } \\
\text { kullanım } \\
\text { kolaylığı }\end{array}$ & 0,407 & $\begin{array}{l}\text { Cinsiyete göre } \\
\text { anlamlı değişim } \\
\text { bulunamamıştır. }\end{array}$ \\
\hline H6 & $\begin{array}{l}\text { D.B. Kullanma } \\
\text { niyeti }\end{array}$ & $\begin{array}{l}\text { D.B. Algılanan } \\
\text { kullanışl1lık }\end{array}$ & 0,991 & $\begin{array}{l}\text { Cinsiyete göre } \\
\text { anlamlı değişim } \\
\text { bulunamamıştır. }\end{array}$ \\
\hline H7 & $\begin{array}{l}\text { D.B. Kullanma } \\
\text { davranış1 }\end{array}$ & $\begin{array}{l}\text { D.B. Kullanma } \\
\text { niyeti }\end{array}$ & 0,892 & $\begin{array}{l}\text { Cinsiyete göre } \\
\text { anlamlı değişim } \\
\text { bulunamamıştır. }\end{array}$ \\
\hline
\end{tabular}

Skaler değişkenler olan yaş, eğitim ve gelirin, test edilen modeldeki anlamlı bulunan ilişkilerin derecesine etkisini ölçmek amacıyla, bu demografik değişkenlerin ilişkiler üzerindeki yönetici etkisine (moderating effect) bakılmıştır. Toplam 12 test sonucunda, 10 anlaml yönetici etki bulunmuştur (Şekil 5). Yaşı büyük olan kişilerde, bireysel yenilikçiliğin algılanan kullanım kolaylığına etkisi daha belirgindir. Benzer şekilde, bu kişilerde kullanma niyetinin kullanma davranışına etkisi daha fazladır. Eğitim durumu tüm ilişkiler üzerinde yönetici etkiye sahiptir. Bireysel yenilikçiliğin algılanan kullanım kolaylığına etkisi, eğitim durumu yüksek bireylerde, düşük olanlara göre daha fazladır. Ancak, algılanan kullanım kolaylığının algılanan kullanışlılığa etkisine bakıldığında durum tam tersidir. Eğitimli düzeyi düşük olan bireylerde algılanan kullanım kolaylığının algılanan kullanışlılık üzerine etkisi, eğitim düzeyi yüksek olan bireylere göre daha yüksektir. Eğitim düzeyinin yüksek olması, niyetin davranışa dönüşmesinde de artırıcı bir etkiye sahiptir. Dördüncü demografik değişken olan aylık gelir düzeyinin de yönetici etkileri gözlemlenmiştir. Örneğin, bireysel yenilikçilik düzeyinin algılanan kullanım kolaylığına etkisi, gelir düzeyi yüksek bireylerde, düşük olanlara göre daha yüksektir. Yani gelir düzeyinin yüksekliği, bu ilişkiyi olumsuz etkilemektedir. $\mathrm{Bu}$ durum, diğer ilişkiler için de geçerlidir.

Son olarak, modelde yer alan toplam 5 değişkenin demografik değişkenlere göre farklılaşmaları test edilmiştir. $\mathrm{Bu}$ amaçla, cinsiyet için t-testi, yaş için doğrusal regresyon ve eğitim durumu ile aylık gelir için tek yönlü varyans analizi (One way ANOVA) kullanılmıştır. Bu analizlerin sonuçlarına göre;

1. Erkekler tüm değişkenlerde kadınlara göre daha yüksek bir düzeye sahiptir.
2. Hiçbir değişken yaşa göre farklılaşmamaktadır. Diğer bir deyişle, katılımcıların yaşı değişkenler üzerinde belirleyici olmamıştır.

3. Dijital bankacılık ile ilgili algılanan kullanışlılık ve kullanma davranışı, eğitim durumuna göre farklılaşmaktadır. Bireysel yenilikçilik, algılanan kullanım kolaylığı ve kullanma niyeti ise eğitim durumundan bağımsızdır.

a. Algılanan kullanışlılık düzeyi, yüksek lisans mezunlarında lise mezunlarına kıyasla anlamlı şekilde daha fazladir.

b. Kullanma davranışı lisans, yüksek lisans ve doktora mezunlarında lise mezunlarına kıyasla anlamlı şekilde daha fazladir.

4. Dijital bankacılık ile ilgili algılanan kullanım kolaylığ algılanan kullanışlılık, kullanma niyeti ve kullanma davranış1, aylık gelir durumuna göre farklılaşmaktadır. Bireysel yenilikçilik ise aylık gelirden bağımsızdır.

a. Algılanan kullanım kolaylığı düzeyi, görece yüksek gelir grubuna mensup kişilerde anlamlı şekilde daha fazladir.

b. Algılanan kullanışlılık düzeyi, görece yüksek gelir grubuna mensup kişilerde anlamlı şekilde daha fazladır.

c. Kullanma niyeti, görece yüksek gelir grubuna mensup kişilerde anlamlı şekilde daha fazladır.

d. Kullanma davranışı, görece yüksek gelir grubuna mensup kişilerde anlamlı şekilde daha fazladır.

\section{SONUÇ (CONCLUSION)}

Bankacılık sisteminin ve bilgi güvenliğinin tüm dünyada gelişmesi ile birlikte Türkiye'de de bu yönde önemli değişimler olmuştur. Bunlardan birisi de bireysel kullanıcıların, internet bankacılığı ve mobil bankacılığı içinde barındıran dijital bankacılığı daha fazla kullanmaya başlamasıdır. Ancak halen bu araçları kullanmayan bireysel kullanicilar da mevcuttur. Literatürde bu kullanımı tetikleyen faktörler incelenmiştir. Türkiye'de de bu alanda yapılan çalışmalar mevcuttur. $\mathrm{Bu}$ çalışmada da bireysel yenilikçilik değişkeni, Teknoloji Kabul Modeli (TKM) üzerine etki eden diş etken olarak değerlendirilmiş ve toplanan verilerle bu etki test edilmiştir.

Çalışma sonucunda, kişilerin bireysel yenilikçilik düzeylerinin dijital bankacılık kullanım niyetleri üzerinde direkt olmasa da dolaylı bir etkisi mevcuttur. $\mathrm{Bu}$ dolaylı etki, algılanan kullanım kolaylığı ve algılanan kullanışlılık üzerinden gerçekleşmiştir. Diğer bir deyişle, yeniliklere açık ve yeni teknolojileri kullanmaya yatkın olan bireyler, dijital bankacılık kullanırken kullanım kolaylığı yaşamaktadır ve zorlanmamaktadır. Buna benzer 
şekilde, bu bireyler dijital bankacılığın kullanışlı olduğunu düşünmektedirler. $\mathrm{Bu}$ ilişki, TKM temelli modellerde yer alan bir ilişkidir. Dijital bankacılık ile ilgili algılanan kullanışlılık düzeyi yüksek olan bireylerin bu araçları kullanma niyeti de yüksektir. $\mathrm{Bu}$ da yine TKM'de yer alan bir ilişkidir. Dolayısıyla, TKM'de yer alan etkiler, bu çalışma için doğrulanmıştır. Dijital bankacılık kullanımı, TKM ile açıklanabilmektedir. Diğer yandan, modelde kullanılan değişkenlerin ve tek yönlü ilişkilerin demografik değişkenlere göre farklılaştığ görülmüştür. Örneğin, modelde yer alan değişkenlerin tamamında erkeklerin kadınlara göre daha yüksek ortalamaya sahip olduğu görülmektedir. Bu durum, literatürdeki birçok bulguyla paralellik göstermektedir. Bunun yanında, cinsiyetin tek yönlü ilişkilerin büyüklükleri üzerinde herhangi bir yönetici etkisi bulunamamıştır. Yaş ise hiçbir değişkenin boyutu üzerinde farklılaştırıcı etki oluşturmasa da, tek yönlü ilişkilerden ikisi (H3 ve H7) üzerinde yönetici etkiye sahiptir. Yaş arttıkça ilişkilerin derecesi de artmaktadır. Beklendiği üzere, eğitim durumunun yükselmesi de teknolojinin kabulü noktasında kolaylaştırıcı bir rol oynamaktadır.

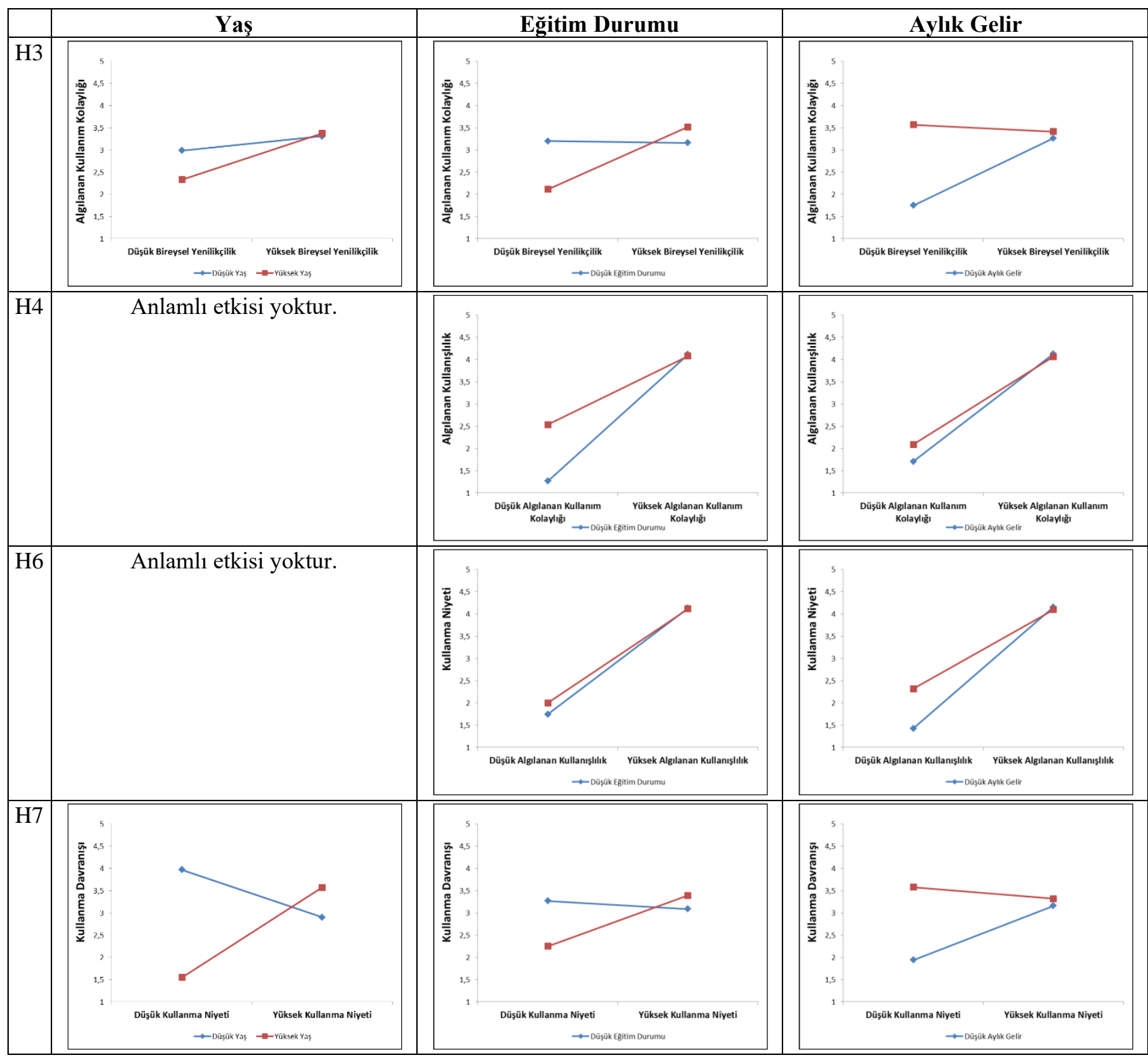

Şekil 5. Demografik değişkenlerin yönetici etkisi (Moderating effect of demographics)

Zira eğitim durumu yüksek kişilerin bireysel yenilikçiliği, algılanan kullanım kolaylığını, diğerlerine göre daha yüksek düzeyde etkilemektedir, yani eğitim bu etkiyi arttırıcı bir etkiye sahiptir. Eğitim düzeyinin yüksek olması, kullanma niyetinin kullanma davranışına olan etkisini artırıcı bir etkiye sahiptir. $\mathrm{Bu}$ durum, bilinçli olmanın harekete geçmeye etkisini göstermesi açısından önemlidir. Son olarak, gelir düzeyinin yüksekliği, tüm tek yönlü ilişkileri olumsuz etkilemektedir. Gelir düzeyi yüksek kişilerin birikimlerinin de yüksek olduğu ihtimali düşünülürse, güven ve risk unsurları da işin içine girebilir. Dolayısıyla, gelirleri/birikimleri yüksek olan kişiler, 
dijital bankacılık yerine geleneksel yöntemleri kullanmaya daha yatkın olabilirler. Sonuçta, yol analizine göre "bireysel yenilikçilik-algılanan kullanım kolaylığıalgılanan kullanışlılık-kullanma niyeti-kullanma davranışı" şeklinde anlamlı bir ilişkisel yoldan bahsedilebilir.

Dijital bankacılığın dünyada ve Türkiye'deki gelişim süreci devam etmektedir. Bilgi güvenliği normlarının ve teknolojilerinin hizla gelişmesine rağmen, halen dolandırıcılık vakaları gerçekleşebilmekte ve kullanıcılar mağdur olmaktadır. Basına yansıyan bu olayları gören diğer kullanıcıların dijital bankacılığı kullanma noktasındaki çekinceleri, bu teknolojik aracin yaygınlaşmasının önündeki en büyük engel olarak göze çarpmaktadır. Yine de, bu çalışmada görüldüğü üzere, düşük gelir düzeyine sahip, genç ve yenilikçi bireyler, dijital bankacılığın kullanımını artıran kitle olabilir. Bu alanda çalışan araştırmacılara, güven ve risk gibi değişkenleri de dâhil ederek daha geniş bir model ve geniş bir veri seti oluşturarak çalışmaları önerilmektedir.

\section{KAYNAKLAR (REFERENCES)}

[1] Internet: Türkiye Bankalar Birliği-Bankalarımız, Aralık 2018 Raporu, https://www.tbb.org.tr/Content/Upload/istatistikiraporlar /ekler/1151/Bankalarimiz_2018.pdf, 10.08.2019.

[2] Internet: Türkiye Bankalar Birliği Dijital, İnternet ve Mobil Bankacilık İstatistikleri Aralı 2018 Raporu, https://www.tbb.org.tr/

Content/Upload/istatistikiraporlar/ekler/1108/Dijital-InternetMobil_Bankacilik_Istatistikleri-Aralik_2018.pdf, 10.08.2019.

[3] I. Ajzen, From intentions to actions: A theory of planned behavior Action control, Springer, ABD, 1985.

[4] F. D. Davis, A technology acceptance model for empirically testing new end-user information systems: Theory and results, Doktora Tezi, Massachusetts Institute of Technology, 1986.

[5] F. D. Davis, V. Venkatesh, "A critical assessment of potentia measurement biases in the technology acceptance model: Three experiments.", International Journal of Human Computer Studies, 45(1), 19-45, 1996.

[6] E. B. Diop, S. Zhao, T. Van Duy, "An extension of the technology acceptance model for understanding travelers' adoption of variable message signs", PLOS one, 14(4), 112-126, 2019.

[7] V. Venkatesh, H. Bala, "Technology Acceptance Model 3 and a Research Agenda on Interventions", Decision Sciences, 39(2), 273-315, 2008.

[8] V. Venkatesh, F. D. Davis, "A theoretical extension of the technology acceptance model: Four longitudinal field studies", Management Science, 46(2), 186-204, 2000.

[9] Jr. L. Robinson, G. W. Marshall, M. B. Stamps, "Sales force use of technology: antecedents to technology acceptance", Journal of Business Research, 58(12), 1623-1631, 2005.

[10] R. Agarwal, J. Prasad, "A conceptual and operational definition of personal innovativeness in the domain of information technology". Information systems research, 9(2), 204-219, 1998.
[11] F. D. Davis, R. P. Bagozzi ve P. R. Warshaw, "User acceptance of computer technology: A comparison of two theoretical models", Management science, 35(8), 982- 1002, 1989.

[12] I. Ajzen, M. Fishbein, Understanding Attitudes and Predicting Social Behavior, Prentice-Hall, Englewood Cliffs, NJ, ABD, 1980 .

[13] J. Lu, J. E. Yao, C. S. Yu, "Personal innovativeness, social influences and adoption of wireless Internet services via mobile technology" The Journal of Strategic Information Systems, 14(3), 245-268, 2005.

[14] R. Walczuch, J. Lemmink, S. Streukens, "The effect of service employees' technology readiness on technology acceptance", Information \& Management, 44(2), 206-215, 2007.

[15] O. Nov, C. Ye, "Personality and technology acceptance: Personal innovativeness in IT, openness and resistance to change" In Proceedings of the 41st annual IEEE Hawaii international conference on system sciences (HICSS 2008), 448-448, 2008.

[16] Ç. Altın Gümüşsoy, A. Yeterel, "Fırsat sitelerinden tekrar satın alma kararını etkileyen faktörlerin araştırılması", Bilişim Teknolojileri Dergisi, 9(3), 275-284, 2016.

[17] C.. Güler, "A structural equation model to examine mobile application usability and use", Biliş̧im Teknolojileri Dergisi, 12(3) , 169-181, 2019.

[18] A. Özduman, B. Gök, H. Gökçen, "Mobil telefon kullanıcılarının mobil bağımlılık durumu ve $5 \mathrm{G}$ teknolojisi kabullenme niyeti modellerinin geliştirilmesi”, Bilişim Teknolojileri Dergisi, 13(3) , 269-288, 2020.

[19] W. M. Lassar, C. Manolis, S. S. Lassar, "The relationship between consumer innovativeness, personal characteristics, and online banking adoption", International Journal of Bank Marketing, 23(2), 176-199, 2005.

[20] C. S. Yiu, K. Grant, D. Edgar, "Factors affecting the adoption of Internet Banking in Hong Kong-implications for the banking sector", International journal of information management, 27(5), 336-351, 2007.

[21] S. K. Chitungo, S. Munongo, "Extending the technology acceptance model to mobile banking adoption in rural Zimbabwe", Journal of Business Administration and Education, 3(1), 2013.

[22] H. S. Kwon, L. Chidambaram, "A test of the technology acceptance model: The case of cellular telephone adoption". In Proceedings of the 33rd Annual Hawaii IEEE International Conference on System Sciences, 7, 2000.

[23] J. H. Wu, S. C. Wang, "What drives mobile commerce?: An empirical evaluation of the revised technology acceptance model". Information \& management, 42(5), 719-729, 2005.

[24] B. Hernandez, J. Jimenez, M. J. Martín,. "Extending the technology acceptance model to include the IT decision-maker: A study of business management software", Technovation, 28(3), 112-121, 2008

[25] M. Chow, D. K. Herold, T. M. Choo, K. Chan, "Extending the technology acceptance model to explore the intention to use Second Life for enhancing healthcare education", Computers \& Education, 59(4), 1136-1144, 2012. 
[26] M. Ghazizadeh, J. D. Lee, L. N. Boyle, "Extending the Technology Acceptance Model to assess automation", Cognition, Technology \& Work, 14(1), 39-49, 2012.

[27] S. Y. Park, M. W. Nam, S. B. Cha, "University students" behavioral intention to use mobile learning: Evaluating the technology acceptance model", British journal of educational technology, 43(4), 592-605, 2012.

[28] H. Son, Y. Park, C. Kim, J. S. Chou,. "Toward an understanding of construction professionals' acceptance of mobile computing devices in South Korea: An extension of the technology acceptance model", Automation in construction, 28, 82-90, 2012.

[29] L. G. Wallace, S. D. Sheetz, "The adoption of software measures: A technology acceptance model (TAM) perspective", Information \& Management, 51(2), 249-259, 2014.

[30] N. M. Yaghoubi, E. Bahmani, "Factors affecting the adoption of online banking-an integration of Technology Acceptance Model and Theory of Planned Behavior", International journal of business and management, 5(9), 159-165, 2010.

[31] S. Y. Yousafzai, G. R. Foxall, J. G. Pallister, "Explaining interne banking behavior: theory of reasoned action, theory of planned behavior, or technology acceptance model", Journal of applied social psychology, 40(5), 1172-1202, 2010.

[32] A. Kesharwani, S. Singh Bisht, "The impact of trust and perceived risk on internet banking adoption in India: An extension of technology acceptance model", International journal of bank marketing, 30(4), 303-322, 2012.

[33] I. Lule, T. K. Omwansa, T. M. Waema, "Application of technology acceptance model (TAM) in m-banking adoption in Kenya", International journal of computing \& ICT research, 6(1), 2012.

[34] Internet: C. Yu, Structural equation model, http://www.creativewisdom.com/teaching/WBI/SEM.shtml, 17.10.2016.

[35] C. Meydan, H. Şeşen, Yapısal eşitlik modellemesi AMOS uygulamaları, Detay Yayıncılık, Ankara, 2011.
[36] D. W. McCloskey, "The importance of ease of use, usefulness, and trust to online consumers: An examination of the technology acceptance model with older customers", Journal of organizational and end user computing, 18(3), 47-65, 2006.

[37] A. Field, Discovering statistics using IBM SPSS statistics, 4 Baskı, Sage, ABD, 2013.

[38] T. A. Shao, Marketing Research: An aid to Decision Making, SouthWestern, Thomson Learning, ABD, 2002.

[39] H. F. Kaiser, "The varimax criterion for analytic rotation in factor analysis", Psychometrika, 23(3), 187-200, 1958.

[40] G. Darren, P. Mallery, SPSS for windows step by step: A simple guide and reference, 4 Bask1, Allyn \& Bacon, Boston, ABD, 2003.

[41] C. Fornell, D. F. Larcker, "Evaluating structural equation models with unobservable variables and measurement error", Journal of marketing research, 18(1), 39-50, 1981

[42] J. F. Hair, W. C. Black, B. J. Babin, R. E. Anderson, Multivariate data analysis, 7 Baskı, Pearson Education, Londra, İngiltere, 2014.

[43] K. Schermelleh-Engel, H. Moosbrugger, H. Müller, "Evaluating the fit of structural equation models: Tests of significance and descriptive goodness-of-fit measures", Methods of psychological research online, 8(2), 23-74, 2003.

[44] R. E. Schumacker, R. G. Lomax, A beginner's guide to structural equation modeling, Taylor \& Francis, ABD, 2004.

[45] L. T. Hu, P. M. Bentler, "Fit indices in covariance structure modeling: Sensitivity to underparameterized model misspecification", Psychological methods, 3(4), 424, 1998.

[46] J. Jaccard, C. K. Wan, Lisrel approaches to interaction effects in multiple regression, Sage, ABD, 1996.

[47] R. B. Kline, Principles and practice of structural equation modeling, Guilford publications, New York, ABD, 2015.

[48] N. Görz, L. Hildebrandt, D. Annacker, "Analyzing multigroup data with structural equation models", Proceedings of the $23 \mathrm{rd}$ Annual Conference of the GfKl, 312-319, 2000. 